\title{
Structure and annealing behavior of an Al-Mg-TM alloy processed by equal channel angular pressing
}

\author{
E. V. Avtokratova ${ }^{1 \dagger}$, O. E. Mukhametdinova ${ }^{1}$, O. Sh. Sitdikov ${ }^{1}$, M. V. Markushev ${ }^{1}$, \\ S. V. S. N. Murty², M. J. N. V. Prasad ${ }^{3}$ and B. P. Kashyap 3 \\ †avtokratova@imsp.ru
}

${ }^{1}$ Institute for Metals Superplasticity Problems RAS, Khalturin St. 39, 450001, Ufa, Russia

${ }^{2}$ Vikram Sarabhai Space Center, Trivandrum-695022, Kerala, India

${ }^{3}$ Indian Institute of Technology Bombay, Powai, Mumbai-400076, India

Effects of equal-channel angular pressing (ECAP) at $325^{\circ} \mathrm{C}$ to a strain, $e \sim 10$, and post-ECAP annealing for $1 \mathrm{hr}$ in the temperature range of $350-520^{\circ} \mathrm{C}$ on structure of the cast and homogenized Al-Mg-Sc-Zr alloy 01570C were analyzed. It is found that annealing of ECAP processed material containing near homogeneous ultrafine-grained structure with $\sim 1 \mu \mathrm{m}$ grain size led to normal grain growth, accompanied by coarsening of $\mathrm{Al}_{3}(\mathrm{Sc}, \mathrm{Zr})$ dispersoids. As compared to the cast alloy, the coarsening of dispersoids in the deformed alloy started at lower temperature and occurred more intensely, and resulted in more rapid loss of their coherency with surrounding matrix.

Keywords: aluminum alloy, severe plastic deformation, ultrafine-grained structure, annealing, dispersoids.

\section{Introduction}

The major characterization of ultrafine-grained (UFG) (grain size, $\mathrm{d}<1 \mu \mathrm{m}$ ) aluminum alloys, especially processed by severe plastic deformation (SPD) [1-5], involves study of their stability at the subsequent heat and thermo-mechanical treatments. The latter is strongly dependant on alloy and phase compositions, and processing route that determine homogeneity and non-equilibrium conditions of grain and grain boundary structures. Further, the volume fraction, dispersion, density, distribution of second phase particles and precipitates, texture and etc. influence the stability of UFG aluminum alloys. It has been known that many aluminum alloys demonstrate poor thermal stability, which significantly limits their applications. Substantial improvements can be achieved by small additions of transition metals (TM), forming high densities of dispersed aluminides (so called dispersoids) and thereby preventing active grain boundary migration, and thus suppressing recrystallization [6-8]. According to numerous data published [e.g., 6-10], the most effective conventional stabilizers are coherent $\mathrm{Zr}$ and $\mathrm{Sc}$ aluminides $-\mathrm{Al}_{3}(\mathrm{Sc}, \mathrm{Zr})$. However, the role of these precipitates on thermal and mechanical behavior of SPD UFG alloys is still not well understood, particularly at high temperatures, when the particles may somewhat loose their stability in themselves. Thus, the present work is aimed towards analyzing the effect of $\mathrm{Al}_{3}(\mathrm{Sc}, \mathrm{Zr})$ dispersoids on UFG structure of Al-Mg-TM alloy processed by equalchannel angular pressing (ECAP) as well as upon subsequent annealing in the temperature range common to structural superplasticity.

\section{Material and procedure}

Plates of $\sim 25 \mathrm{~mm}$ thick, cut out from the cast and homogenized (at $350{ }^{\circ} \mathrm{C}$ for $6 \mathrm{hrs}$ ) ingot of the commercial alloy $\quad 01570 \mathrm{C} \quad(\mathrm{Al}-5 \mathrm{Mg}-0.18 \mathrm{Mn}-0.2 \mathrm{Sc}-0.08 \mathrm{Zr}-0.01 \mathrm{Si}-0$ $.01 \mathrm{Fe}$, wt.\%), were subjected to ECAP at a temperature of $325^{\circ} \mathrm{C}$ to 10 (an effective strain, e 10) passes. The alloy in homogenized as well as in as-ECAPed conditions was further annealed for $1 \mathrm{hr}$ in the temperature range of $350-520^{\circ} \mathrm{C}$. Standard methods of optical metallography (OM) and transmission electron microscopy (TEM) were used for microstructure analysis. The microhardness measurement was also done by standard procedure using Vickers indenter.

\section{Results and discussion}

Microstructure of the homogenized ingot consists of equiaxed grains with an average size of $\sim 25 \mu \mathrm{m}$ (fig. 1a). Inside the grains there were rather evenly distributed nanosized coherent precipitates of $\mathrm{Al}_{3}(\mathrm{Sc}, \mathrm{Zr})$ phases (indicated in fig. $1 \mathrm{~b}$ by black arrows) with relatively weak delta-zero diffraction contrast.

Upon ECAP to 10 passes there formed almost uniform UFG structure (fig.2a) with $\sim 1 \mu \mathrm{m}$ grains separated by sharp boundaries with distinct extinction contours (fig.2b). Such structure evolved was characterized by low dislocation density and high density of coherent $\mathrm{Al}_{3}(\mathrm{Sc}, \mathrm{Zr})$ dispersoids in grain interiors, as seen in fig.2c.

According to the images in figs.3a-c, the main structural changes during annealing of the alloy with the UFG structure were governed by normal grain growth, where the grain size increased from $\sim 1 \mu \mathrm{m}$ to just $5 \mu \mathrm{m}$ after annealing at temperatures above $450{ }^{\circ} \mathrm{C}$, while there was limited grain growth at lower temperatures. The controlled grain growth in this alloy could be related to the presence of dispersoids. There also occurred coarsening of these dispersoids with concurrent decrease in their density with increasing annealing temperature as illustrated in figs.4a-c for non- 

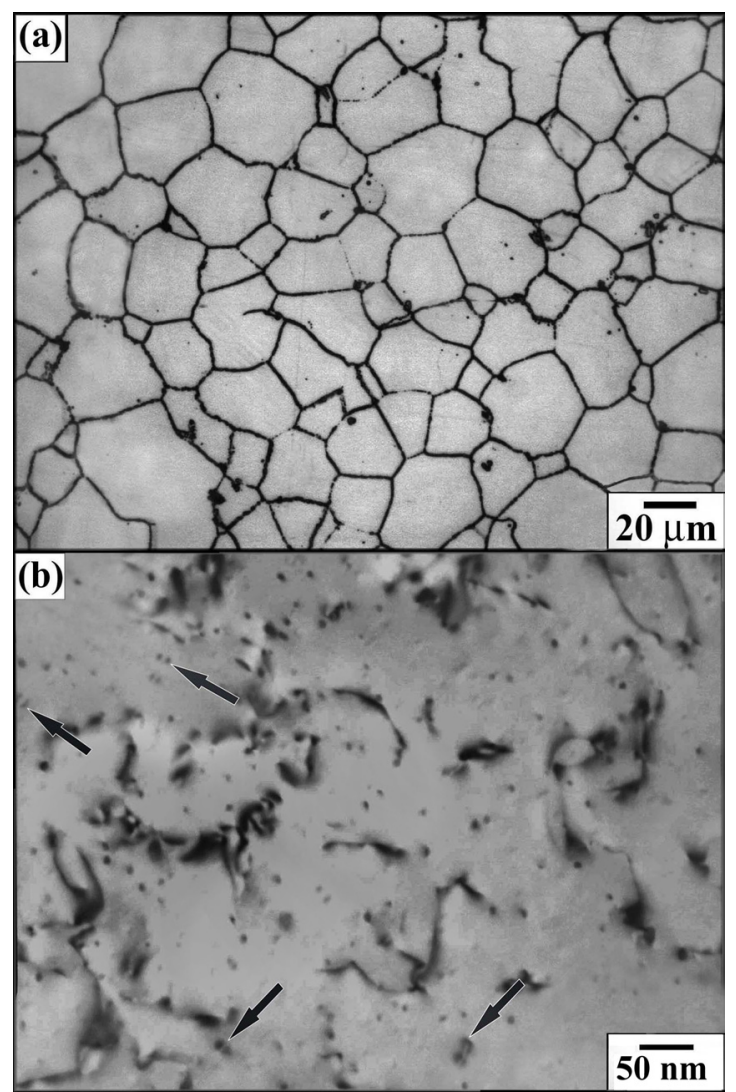

Fig. 1. OM (a) and TEM (b) structures of the homogenized ingot of alloy 01570C.

deformed (homogenized) alloy. Moreover, the delta-zero contrast in the bright-field TEM images also suggests that these phases remain coherent within the matrix, even after annealing close to the melting point. To the contrary, in the UFG structure, coarsening of dispersoids was not only faster, but also caused the loss of their coherency with annealing temperature. Figure 5 reveals the presence of high density of incoherent compact spherical particles in the UFG alloy annealed even at $450{ }^{\circ} \mathrm{C}$.

Hardness measurement has shown similar values of microhardness ( 106 and $\sim 108 \mathrm{Hv}$, respectively) for the non-deformed and as-ECAPed to $e \sim 10$ conditions (fig.6). Most probably, such «zero - effect» of ECAP on the alloy hardness could be ascribed to a superposition of structural factors that provide the alloy strengthening or softening under SPD carried out at elevated temperature. The first one is conditioned by grain refinement (Hall-Petch effect) and the second one by partial lost of disperse strengthening owing to dispersoids coarsening. At that the deformation strengthening was also minimized by high-temperature conditions of ECAP due to extensive operation of dynamic recovery resulted in equilibrium (sub)grain structure, as shown in fig.2b.

Based on the data presented in fig.6, the thermal stability of the alloy in SPD condition is lower than that of the initial alloy. In the temperature range of $20-400{ }^{\circ} \mathrm{C}$, the hardness of ECAP alloy gradually decreases with annealing temperature and then drops quite fast at higher temperatures, whereas this trend is delayed to the temperature of $450^{\circ} \mathrm{C}$ in the nondeformed alloy.

The above analysis also indicates that annealing of as-ECAPed alloy led to significant changes in morphology of secondary aluminides of TM. Grain growth in the UFG structure can result in simultaneous loss of coherency of $\mathrm{Al}_{3}(\mathrm{Sc}, \mathrm{Zr})$ dispersoids, as was shown in [11]. This loss in coherency accelerates particle coarsening through coagulation [12], as seen in fig.5. Coarsening of dispersoids, being accompanied by loss of their coherency within the matrix, along with the contribution of concurrent grain
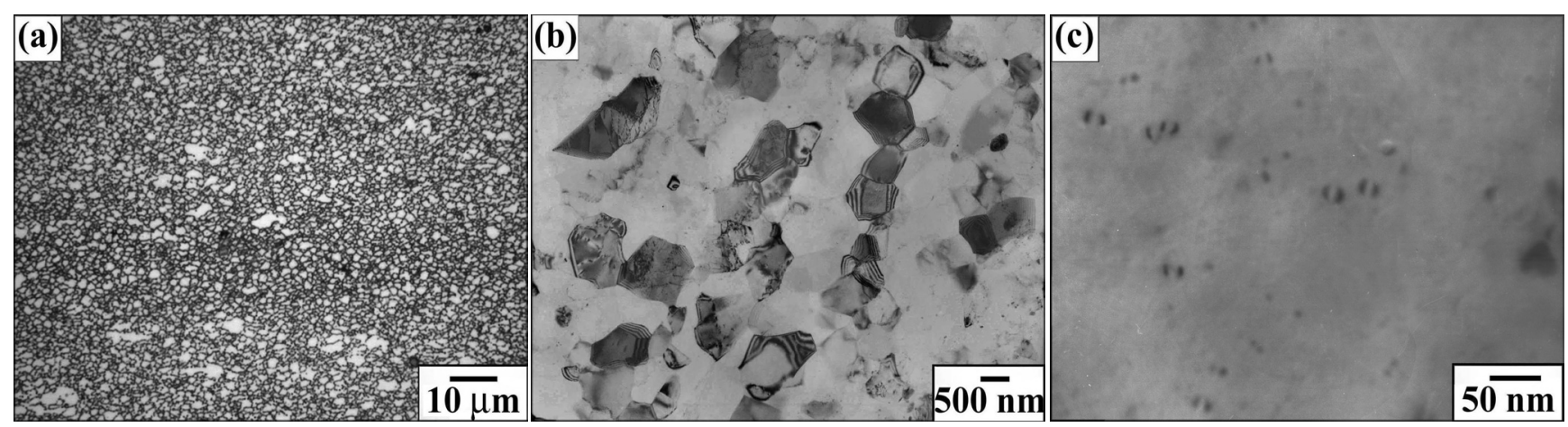

Fig. 2. OM (a) and TEM (b, c) structures of an alloy 01570C after ECAP to $e \sim 10$.

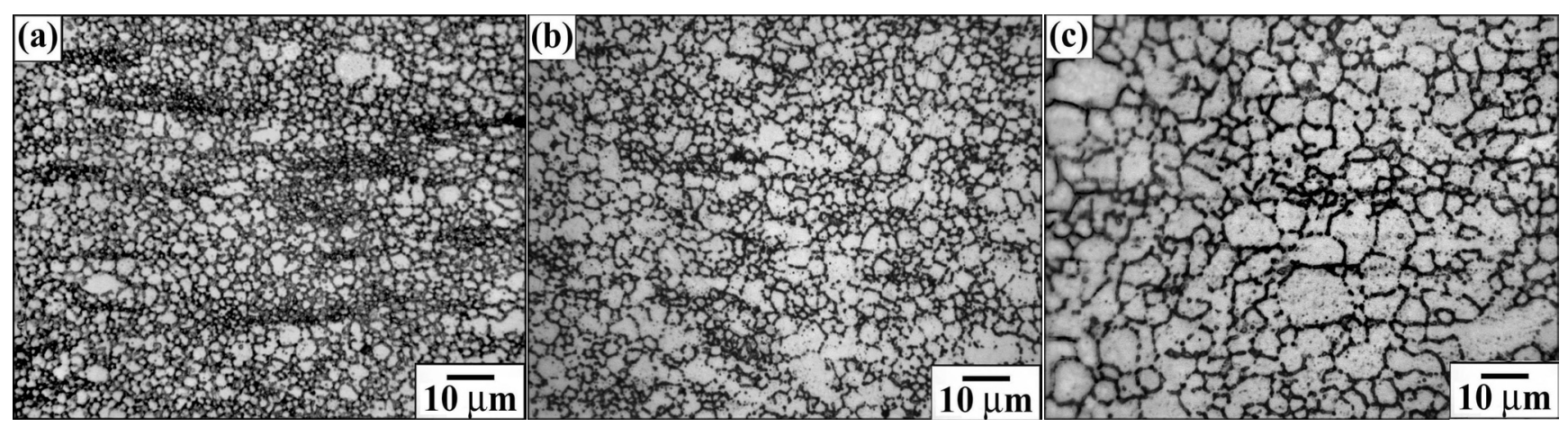

Fig. 3. OM alloy $01570 \mathrm{C}$ structure after ECAP and subsequent $1 \mathrm{hr}$ annealing at 450 (a), 475 (b) and $520^{\circ} \mathrm{C}$ (c). 

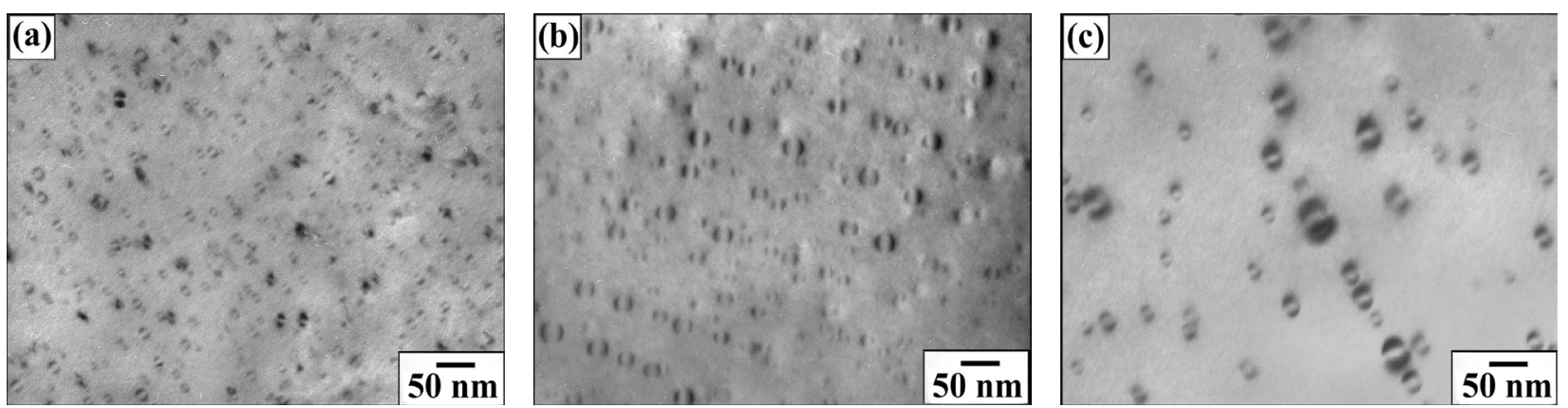

Fig. 4. Dispersoids in non-deformed alloy $01570 \mathrm{C}$ after annealing for $1 \mathrm{hr}$ at 450 (a), 475 (b) and $520^{\circ} \mathrm{C}$ (c).

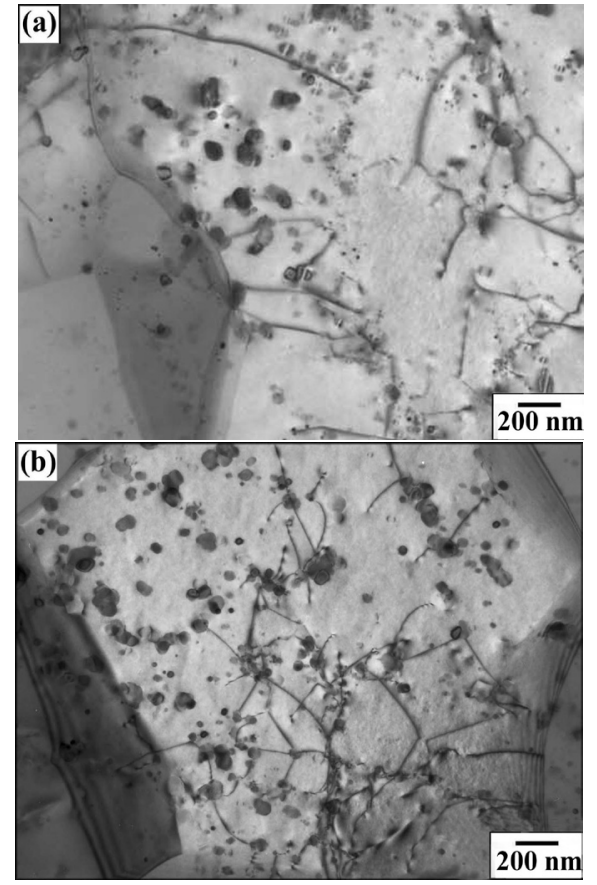

Fig. 5. Dispersoids in the alloy 01570C subjected to ECAP and subsequent annealing for $1 \mathrm{hr}$ at 450 (a) and $475^{\circ} \mathrm{C}(\mathrm{b})$.

growth, is suggested to be the main reason for the more rapid alloy decrease in hardness with annealing temperature. It should be, however, noted that, in spite of the changes mentioned, these precipitates remain randomly dispersed and highly dense, which could be the source for the observed thermal stability of grain structure. This could therefore be the main reason for extraordinary superplastic behavior of the UFG 01570C alloy reported earlier [13].

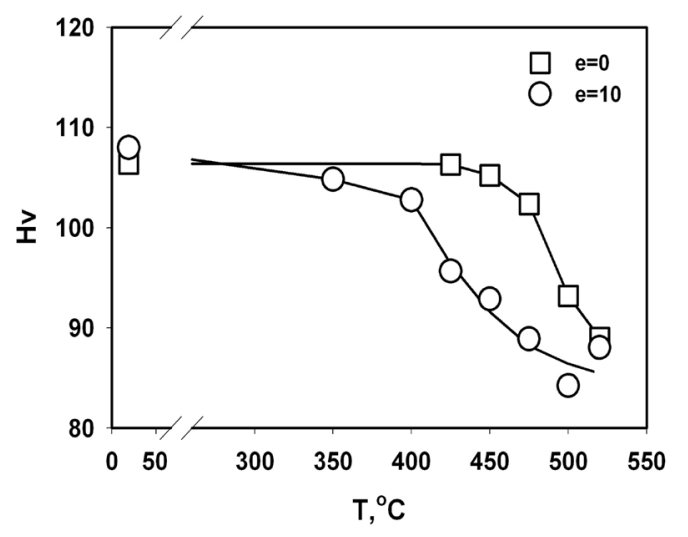

Fig. 6. Microhardness (Hv) vs annealing temperature (T) for $1 \mathrm{hr}$ of the as cast and ECAP alloy 01570C.

\section{Conclusions}

After 10 passes of ECAP of as cast alloy $01570 \mathrm{C}$ at a temperature of $325{ }^{\circ} \mathrm{C}$, a uniform UFG structure with an average grain size of $\sim 1 \mu \mathrm{m}$ was obtained. However, such a processing did not result in any enhancement of microhardness over homogenized condition. With increasing annealing temperature, the hardness remained practically unchanged up to the temperature of $400{ }^{\circ} \mathrm{C}$, but decreased rapidly at higher temperatures. Coarsening of dispersed secondary $\mathrm{Al}_{3}(\mathrm{Sc}, \mathrm{Zr})$ phases with loss of coherency along with grain growth could be the main reason for the alloy decrease in hardness.

This study was partially supported by RFBR, research project No 13-08-92700a and by DST, project No. INT/RUS/RFBR/P-161.

\section{References}

1. Z.Y. Ma, F.C. Liu, R.S. Mishra. Acta Mater. 58, 4693 (2010).

2. M.V. Markushev, Letters on Mater. 1, 36 (2011) (in Russian).

3. R. Z. Valiev, I. Sabirov, A. P. Zhilyaev, T. G. Langdon. JOM. 64 (10), 1134 (2012).

4. O. Sitdikov, E. Avtokratova, R. Babicheva, T. Sakai, K. Tsuzaki and Y. Watanabe. Mater. Trans. 53 (1), 56 (2012).

5. T. G. Langdon. Acta Materialia 61,7035 (2013).

6. V. I. Elagin. Mat. Sci. Heat. Treat. 93, (2007).

7. R. Roumina, C. W. Sinclair. Acta Mater. 58,111 (2010).

8. D. Tsivoulas, J. D. Robson, C. Sigli, P. B. Prangnell. Acta Materialia 60, 5245 (2012).

9. S. Lee, A. Utsunomiya, H. Akamatsu, Acta Mater. 50, 553 (2002).

10. J. L. Ning, D. M. Jiang, Mater. Sci. Eng A. 452-453, 552 (2007).

11. J. Royset, N. Ryum, Int. Mater. Reviews 50,19 (2005).

12. O. Sitdikov, T. Sakai, E. Avtokratova et al. Acta Mater. 56, 821 (2008).

13. E. Avtokratova, O Sitdikov, M Markushev, R Mulyukov, Mater. Sci. Eng. A. 538, 386 (2012). 